\title{
Anger Expression Style among Nurses Working in General Hospitals of Karachi, Sindh, Pakistan
}

\author{
Suriya Khatoon ${ }^{1}$ (D), Syed Yousaf Shah'², Ajmal Khan ${ }^{3}$, Syed Arif Ali² \\ ${ }^{1}$ Shaheed Mohtarma Benazir Bhutto Medical University, Larkana, Pakistan \\ ${ }^{2}$ Dow University of Health Sciences, Karachi, Pakistan \\ ${ }^{3}$ Indus College of Nursing \& Midwifery, Karachi, Pakistan \\ Email: suriya.nisar@gmail.com, sayedyousafshah@gmail.com, ajmalkhan320@gmail.com, arif_ali79@hotmail.com
}

How to cite this paper: Khatoon, S., Shah, S.Y., Khan, A. and Ali, S.A. (2019) Anger Expression Style among Nurses Working in General Hospitals of Karachi, Sindh, Pakistan. Open Journal of Nursing, 9, 370-382. https://doi.org/10.4236/ojn.2019.94034

Received: February 27, 2019

Accepted: April 14, 2019

Published: April 17, 2019

Copyright $\odot 2019$ by author(s) and Scientific Research Publishing Inc. This work is licensed under the Creative Commons Attribution International License (CC BY 4.0).

http://creativecommons.org/licenses/by/4.0/

\begin{abstract}
Background: Nowadays, the medical environment has become more competitive in terms of fulfilling various desires of client and to deliver improved service. Repetitive and continued stress may lead anger. Anger is defined as a natural emotion that triggers self-protection mechanism in oneself in a stressful condition. Extreme stress or if duration and intensity of anger are uncontrollable then it could have a negative impact on physical health which can further cause difficulties such as inadequate life, interpersonal issues and depression. Objectives: To find out anger expression style among nurses who work in the hospitals of Karachi, Pakistan, and to assess the association between interpersonal problems and levels of anger expression. Methods: This cross-sectional study was conducted at Dow University Hospital and Civil Hospital Karachi from July to August 2017. The data were collected through a structured questionnaire. The questionnaire was based on two parts: the first part was related to demographic form and it was comprised of 10 questions. The second part has two forms, which includes the Stat Trait anger inventory (STAIX) and Korean Inventory of Interpersonal Problems Circumplex Scales (KIIP-SC). Results: Data were gathered from 196 participants working in shifts. More than half of the study participants were young (26 - 35-year-old). To the extent that interpersonal problems were regarded, nurses were negatively associated with state anger and trait anger where positive associations were found with anger control, anger in and anger out. This research exhibited consistent moderate correlation for cold vindictive among anger control, anger in and anger out. This study exhibited that the groups that had the most difficulty with interpersonal problems are the anger-in and out groups. Conclusion: It is concluded that anger expression types trait-anger, stat-anger, anger in, anger control and anger out were not at higher side and showed weaker characteristics of respective subgroups. Similarly, interper-
\end{abstract}


sonal problems were also at the lower side and exhibiting lighter characteristics of respective subgroups.

\section{Keywords}

Anger, Interpersonal Problem, Anger Expressions

\section{Introduction}

Currently, the medical environment has become more competitive in terms of fulfilling various needs of the client and to deliver better service. Literature shows that stress level of an individual working in a general office environment is not as much as that of hospital workers [1]. Stress level has been found more prevalent as compared to other professionals in a medical environment because nurses are supposed to provide first hand service to patients and families [2]. Repetitive and continued stress can lead anger. Anger is defined as a natural emotion that triggers self-protection mechanism in oneself in a stressful condition. Extreme stress or if duration and intensity of anger are uncontrollable then it could have a negative impact on physical health [3] [4] which can further cause issues like inadequate life, depression and interpersonal issues [5] [6]. There are two distinct concepts, anger experience, and anger expression. Anger experience means the state of emotion one feels. Furthermore, it is associated with a physiological response. Whereas, anger expression means a behavioral dimension (one method of handling anger). The literature on expression of anger reveals three distinguishable types of anger appearance: anger-in sight, anger-out sight and anger-command [7] [8]. Anger-in means renunciation of thoughts associated with the situation that triggers anger and redirection of anger to self. Anger-out means stating anger to other individuals in several ways, even with physical action, affront and spoken abuse. Anger-controlmeans trying to manage and control anger, and to show anger with due respect of emotions and rights of the other individuals by employing words that are not harsh and aggressive [7].

Few studies revealed that anger expression style was more adequate with respect to age. Individuals had more appropriate anger expression style in older age as compared to younger age [9]. In nurse related studies it was mentioned that style of anger expression was associated with psychological, physical health conditions [10] [11]. It was also found that anger expression style had an impact on the professional environment such as the performance of an organization and satisfaction in the job. There are several research studies that compared relationship among anger appearance style and interactive harms in different groups such as children [12], adults [13] and students [14]. Results revealed that individuals who used anger-control style were found to be with minimum interpersonal problems. Ersoy [15] conducted a research study in 2009 to identify the relationship among social support, the experience of anger and burnout among 
emergency nurses. That study revealed that according to burnout subscale score, social support did not differentiate in nurses working in public and private sectors. But it was found that public sectors nurses had more difficulty in expressing anger. Moreover, a study, where surveys of WHO-World Mental Health were analyzed, revealed that in many countries anxiety-mood disorders were more widespread among adult women as compared to men [16]. In another study [17] it was observed that Korean girls showed less positive emotions and exhibited substantially greater trait anger as compared to boys. Literature shows that life stress at times directs to negative emotions such that worry, anxiety, depression, and anger) [18]. Korean nursing students exhibit substantially higher anger as compared to engineering students or natural sciences [19]. In the nursing profession anger is a key emotional issue appearing due to stress [20]. Anger might affect negatively to the quality of care that nursing professionals deliver [20] [21]. Hence, focusing nursing professionals/students with high anger, nursing teaching must provide anger managing training. An earlier study shows that anger managing plans must focus individual approaches of anger expression [19]. For instance, a person who represses his/her anger might seem to calm however, experience delayed emotional recovery. Jun (2016) explored that among Korean students the trait anger greatest powerfully affected anger-out. Such findings together advise that anger levels differ based on the method of expression employed.

In nursing profession, interpersonal problems and anger expression style are linked to each other as straightforward associated with the work performance of a nurse and mental health, consequently affecting the quality of nursing. Regardless of researchers showing that interpersonal relationships trigger anger and the explanation that the anger expression style performs a substantial role in interpersonal issues, there are limited researches that show understanding of anger expression style and its subgroups among nurses, who are responsible for cooperating with patients and their families. There was no previous such study in Pakistan; that motivated us to conduct this study that might explain the understanding of anger expression style in the nursing profession in Pakistan. The objective of this research was to recognize anger expression style among nurses who work in the hospitals of Karachi, Pakistan, and to assess the association between interpersonal problems and levels of anger expression.

\section{Methodology}

This observational study was accomplished at Civil Hospital and Dow University Hospital Karachi from July to August 2017. Registered nurses working in all shifts were recruited through non-probability consecutive sampling. All student nurses of $1^{\text {st }} 2^{\text {nd }}$ and $3^{\text {rd }}$ year were excluded. Sample size calculation was carried on WHO online software Open Epi. With the help of $49.7 \%$ nurses having a high score of anger-in, 7\% margin of error and confidence interval ad $95 \%$ the resultant sample size was 196 nurses.

Data were collected through a structured questionnaire. The questionnaire 
was comprised of two parts; the first part was related to demographic. The second part has two forms, Stat Trait anger inventory (STAIX) (see Appendix 1) and Korean Inventory of Interpersonal Problems Circumplex Scales (KIIP-SC) (see Appendix 2) STAIX consisted of 44 questions, a scale based on five sub-domains (Anger In, Anger Out and Anger Control, State Anger and Trait Anger), This tool uses four points Likert scale with 4 signifying strongly agree and 1 signifying strongly disagree. Higher points signify solid features of the related sub-factor. Furthermore, a high sum of the points for the five sub-factors signifies frequent anger expressions regardless of anger expression type. Korean Inventory of Interpersonal Problems Circumplex Scales (KIIP-SC), 32 questions on interpersonal problems having eight subdomains; Cold, Intrusive problem and Socially Avoidant, Vindictive, Nonassertive, Domineering, Exploitable and Overly Nurturing. In this tool, 4 showing strongly agree and 0 means strongly disagree with five points Likert scale. Each sub-factor has the range of 0 to 20 points, with higher scores signifies more difficulties in each interpersonal problem of sub-factors.

Data were entered and analyzed on SPSS 21.0. Descriptive statistics were calculated for the demographic, State-Trait Anger Expression Inventory and Inventory of Interpersonal Problems Circumplex Scales (IIP-SC). Pearson Correlation Coefficients test was used to assess the relationship between (STAXI) and (IIP-SC) among nurses.

\section{Results}

Table 1 shows properties of nurses participated in this study. More than half a cent of the study participants was young (26 - 35-year-old) and only $5.1 \%$ participants were middle aged (>45). There was $53.6 \%$ male and $46.4 \%$ was female participants. Two-third of nurses were working in government sectors whereas only $32.7 \%$ belonged to private sectors. Most of the participants (70.9\%) were registered nurse and only $6.1 \%$ and $12.8 \%$ were a head nurse and assistant head nurse respectively.

Table 2 represents summary statistics of Stat-Trait Anger Expression Inventory among nurses. Mean of sum scores of state-anger was 14.9 with standard deviation of 6.87 a with maximum summed state anger score of 38.0. Similarly means of summed scores of, anger control, trait anger, anger out and anger in sub factors were $18.12 \pm 5.22,17.64 \pm 6.59,23.84 \pm 6.77,14.32 \pm 4.19$ respectively. These means confirmed that anger expression types trait-anger, stat-anger, anger out, anger control and anger in were not at the higher side.

Table 3 represents summary statistics of for Inventory of interpersonal problems circumplex scales (IIP-SC) items among nurses. Mean of sum scores of domineering was 6.55 with a standard deviation of 2.80 with a maximum summed domineering score of 12.0. Similarly means of summed scores of cold, vindictive, nonassertive, exploitable, overly nurturing, socially avoidant and intrusive confirmed that Inventory of interpersonal problems was not at the higher side. 
Table 1. The percentages of qualities of the nurses.

\begin{tabular}{|c|c|c|}
\hline Qualities & $\mathbf{N}$ & $\%$ \\
\hline \multicolumn{3}{|l|}{ Age (years) } \\
\hline $15-25$ & 55 & 28.1 \\
\hline $26-35$ & 105 & 53.6 \\
\hline $36-45$ & 26 & 13.3 \\
\hline More than 45 & 10 & 5.1 \\
\hline \multicolumn{3}{|l|}{ Gender } \\
\hline Male & 105 & 53.6 \\
\hline Female & 91 & 46.4 \\
\hline \multicolumn{3}{|l|}{ Education level } \\
\hline Matric & 57 & 29.1 \\
\hline Intermediate & 72 & 36.7 \\
\hline Graduate & 59 & 30.1 \\
\hline Post-graduate & 8 & 4.1 \\
\hline \multicolumn{3}{|l|}{ Marital status } \\
\hline Single & 96 & 49.0 \\
\hline Married & 96 & 49.0 \\
\hline Widow & 4 & 2.0 \\
\hline \multicolumn{3}{|l|}{ Job status } \\
\hline Government job & 132 & 67.3 \\
\hline Private job & 64 & 32.7 \\
\hline \multicolumn{3}{|l|}{ Designation/ Post } \\
\hline Head Nurse & 12 & 6.1 \\
\hline Assistant $\mathrm{H} / \mathrm{N}$ & 25 & 12.8 \\
\hline Registered Nurse & 139 & 70.9 \\
\hline Other & 20 & 10.2 \\
\hline \multicolumn{3}{|c|}{ Monthly income in Rupes } \\
\hline Less than 20,000 & 33 & 16.8 \\
\hline $21,000-40,000$ & 111 & 56.6 \\
\hline $41,000-60,000$ & 38 & 19.4 \\
\hline More than 60,000 & 14 & 7.1 \\
\hline \multicolumn{3}{|l|}{ Duties perform } \\
\hline Morning & 47 & 24.0 \\
\hline Evening & 40 & 20.4 \\
\hline Night & 21 & 10.7 \\
\hline Rotation & 88 & 44.9 \\
\hline Work unit & & \\
\hline
\end{tabular}




\section{Continued}

\begin{tabular}{ccc}
\hline Emergency & 36 & 18.4 \\
ICU & 58 & 29.6 \\
General ward & 80 & 40.8 \\
Other & 22 & 11.2 \\
Duration of work & & \\
06 Hours & 109 & 55.6 \\
08 Hours & 56 & 28.6 \\
12 Hours & 31 & 15.8 \\
\hline
\end{tabular}

Table 2. Mean score, SD, range, min values and max values for State-Trait Anger Expression Inventory (STAXI) among nurses.

\begin{tabular}{cccccc}
\hline STAXI & Mean & Std. Deviation & Range & Minimum & Maximum \\
\hline State Anger & 14.9031 & 6.87439 & 28.00 & 10.00 & 38.00 \\
Trait Anger & 17.6429 & 6.59098 & 29.00 & 10.00 & 39.00 \\
Anger Control & 18.1224 & 5.22865 & 21.00 & 7.00 & 28.00 \\
Anger In & 14.3265 & 4.19957 & 18.00 & 6.00 & 24.00 \\
Anger Out & 23.8469 & 6.77908 & 29.00 & 11.00 & 40.00 \\
\hline
\end{tabular}

Table 3. Mean score, SD, range, s and max values for Inventory of Interpersonal Problems Circumplex Scales (IIP-SC) items among nurses.

\begin{tabular}{ccccc}
\hline IIP-SC & Mean & Std. Deviation & Range & Maximum \\
\hline Domineering & 6.5561 & 2.80328 & 12.00 & 12.00 \\
Vindictive & 5.7551 & 3.79355 & 16.00 & 16.00 \\
Cold & 6.8367 & 3.87945 & 14.00 & 14.00 \\
Socially Avoidant & 6.1735 & 3.31593 & 15.00 & 15.00 \\
Nonassertive & 6.9490 & 3.66794 & 12.00 & 12.00 \\
Exploitable & 7.4286 & 3.55326 & 15.00 & 15.00 \\
Overly Nurturing & 8.6531 & 3.02842 & 14.00 & 14.00 \\
Intrusive & 7.3571 & 3.62116 & 13.00 & 13.00 \\
\hline
\end{tabular}

Table 4 showed correlation analysis between state-trait anger expression inventory and inventory of interpersonal problems circumplex scale. It was observed that there was statistical significant but moderate correlation of anger control, anger in and anger out with all interpersonal problem circumplex scales. Whereas correlations of state-anger and trait-anger with all interpersonal problem circumplex scales were quite low and most of them were statistically insignificant.

\section{Discussion}

In this research, we found that nurses had a low level of trait anger, state anger, 
Table 4. Correlation coefficients between the State-Trait Anger Expression Inventory (STAXI) and Inventory of Interpersonal Problems Circumplex Scales (IIP-SC) items among nurses.

\begin{tabular}{|c|c|c|c|c|c|c|c|c|c|c|}
\hline \multirow{2}{*}{$\begin{array}{l}\text { STAXI } \\
\text { IIP-SC }\end{array}$} & \multicolumn{2}{|c|}{ State Anger } & \multicolumn{2}{|c|}{ Trait Anger } & \multicolumn{2}{|c|}{ Anger Control } & \multicolumn{2}{|c|}{ Anger In } & \multicolumn{2}{|c|}{ Anger Out } \\
\hline & $\mathbf{r}$ & $\mathbf{P}$ & $\mathbf{r}$ & $\mathbf{P}$ & $\mathbf{r}$ & $\mathbf{P}$ & $\mathbf{r}$ & $\mathbf{P}$ & $\mathbf{r}$ & $\mathbf{P}$ \\
\hline Domineering & 0.019 & 0.791 & -0.123 & 0.086 & $0.298^{\star *}$ & $<0.001$ & $0.403^{* *}$ & $<0.001$ & $0.333^{* *}$ & $<0.001$ \\
\hline Vindictive & $-0.145^{*}$ & 0.043 & $-0.241^{* *}$ & 0.001 & $0.315^{\star *}$ & $<0.001$ & $0.478^{* *}$ & $<0.001$ & $0.396^{\star *}$ & $<0.001$ \\
\hline Cold & 0.056 & 0.437 & 0.092 & 0.198 & $0.400^{\star *}$ & $<0.001$ & $0.510^{* *}$ & $<0.001$ & $0.582^{* *}$ & $<0.001$ \\
\hline $\begin{array}{c}\text { Socially } \\
\text { Avoidant }\end{array}$ & 0.022 & 0.760 & 0.050 & 0.491 & $0.353^{\star *}$ & $<0.001$ & $0.439^{* *}$ & $<0.001$ & $0.521^{\star *}$ & $<0.001$ \\
\hline Nonassertive & -0.113 & 0.116 & -0.065 & 0.362 & $0.209^{\star *}$ & 0.003 & $0.342^{* *}$ & $<0.001$ & $0.364^{\star *}$ & $<0.001$ \\
\hline Exploitable & $-0.245^{\star *}$ & 0.001 & -0.112 & 0.118 & $0.181^{\star}$ & 0.011 & $0.237^{\star *}$ & 0.001 & $0.224^{* \star}$ & 0.002 \\
\hline $\begin{array}{c}\text { Overly } \\
\text { Nurturing }\end{array}$ & $-0.169^{\star}$ & 0.018 & $-0.194^{* *}$ & 0.006 & $0.235^{\star *}$ & 0.001 & $0.446^{* *}$ & $<0.001$ & $0.433^{\star *}$ & $<0.001$ \\
\hline Intrusive & 0.019 & 0.791 & -0.123 & 0.086 & $0.298^{\star *}$ & $<0.001$ & $0.403^{* *}$ & $<0.001$ & $0.333^{* *}$ & $<0.001$ \\
\hline
\end{tabular}

anger in, anger control and anger out. Anger is regarded as one of the fundamental human emotion [22] and as a fundamental psychological phenomenon that performs a vital part in the social and personal life of individuals [23]. Anger has been also associated with adverse outcomes of health and is taken as a substantial predictor for longstanding physical health issues like heart diseases [24]. In addition, high anger has been associated with deterioration of individual's functioning and well-being [25].

We determined the association between interpersonal problems and anger expression types. Our findings exhibited that, to the extent that interpersonal issues were concerned, nurses were negatively associated with state anger and trait anger where positive associations were obtained with anger control, anger in and anger out. This research exhibited consistent moderate correlation for cold vindictive among anger control, anger in and anger out [26].

This study exhibited that the groups that had the maximum difficulty with interpersonal issues are the anger-in and out groups. Emotional suppression may perform as a constraining factor for anger expression [13]. This result is in accord with the results of the study [14] that declared that suppression-type anger showed generally high interpersonal problems, specifically like nonassertive, egocentric, cold and avoidant.

Although consistent with previous studies, anger repression, a style of anger expression, was identified as an important factor that causes interpersonal problems. For instance, according to a study [27] found that while anger repression had a substantial impact on interpersonal problems, anger control did not, in school students of the middle class.

Another research [13] also reported that there were moderate influences of the anger-in type that incite interpersonal problems like nonassertive, over- 
ly-nurturing, socially avoidant and self-sacrificing actions among individuals working in office environment. Thus, it is a finding in this study that anger-control is not noticeably correlate among interpersonal issues but anger in is. In this study, anger-in exhibited relatively high correlation in all interpersonal issues than that of control and out. This might be explained as the anger-control type having the tendency to experience lower interpersonal problems. Whereas, anger in more likely to express high interpersonal problems. State anger and trait anger in all interpersonal problems have negative and low correlations this shows that state anger and trait anger having the tendency to experience lower interpersonal problems.

\section{Conclusion}

From this research, it is concluded that anger expression types trait-anger, stat-anger, anger in, anger control and anger out were not at higher side and showed weaker characteristics of respective subgroups. Similarly, interpersonal problems were also at the lower side and exhibiting lighter characteristics of respective subgroups. There were moderate statistically significant associations of anger control, anger in and anger out with interpersonal problems.

\section{Limitation}

This study used convenience sampling for participant selection hence interpretation of the results must be done with caution. Here, for the measurement of anger expression and interpersonal problems only subjective data was used, in the future to augment the results and increase data reliability the objective measurement methods such as observation should be used.

\section{Conflicts of Interest}

The authors declare no conflicts of interest regarding the publication of this paper.

\section{References}

[1] Han, A., Won, J., Kim, O. and Lee, S.E. (2015) Anger Expression Types and Interpersonal Problems in Nurses. Asian Nursing Research, 9, 146-151. https://doi.org/10.1016/j.anr.2015.04.001

[2] AbuAlRub, R.F. (2004) Job Stress, Job Performance, and Social Support among Hospital Nurses. Journal of Nursing Scholarship, 36, 73-78. https://doi.org/10.1111/j.1547-5069.2004.04016.x

[3] Igna, C.V., Julkunen, J. and Vanhanen, H. (2009) Anger Expression Styles and Blood Pressure: Evidence for Different Pathways. Journal of Hypertension, 27, 1972-1979. https://doi.org/10.1097/HJH.0b013e32832f4f8f

[4] László, K.D., Janszky, I. and Ahnve, S. (2010) Anger Expression and Prognosis after a Coronary Event in Women. International Journal of Cardiology, 140, 60-65. https://doi.org/10.1016/j.ijcard.2008.10.028

[5] Kim, K., Song, S. and Sok, S. (2008) A Study on Correlation among Anger, Health 
State, and Quality of Life in the Elderly. Journal of Korean Academy of Psychiatric and Mental Health Nursing, 17, 19-27.

[6] Jang, M.-H., Kim, Y.-H. and Won, J.-S. (2009) Association of Anger and Anger Expression, Social Support, Self-Esteem and Depression in Elderly. Journal of Korean Academy of Psychiatric and Mental Health Nursing, 18, 259-268.

[7] Spielberger, C.D., Jacobs, G., Russell, S. and Crane, R.S. (1983) Assessment of Anger: The State-Trait Anger Scale. Advances in Personality Assessment, 2, 159-187.

[8] Whiteside, S.P. and Abramowitz, J.S. (2005) The Expression of Anger and Its Relationship to Symptoms and Cognitions in Obsessive-Compulsive Disorder. Depression and Anxiety, 21, 106-111. https://doi.org/10.1002/da.20066

[9] Allan, S. and Gilbert, P. (2002) Anger and Anger Expression in Relation to Perceptions of Social Rank, Entrapment and Depressive Symptoms. Personality and Individual Differences, 32, 551-565. https://doi.org/10.1016/S0191-8869(01)00057-5

[10] Kim, S.H., Lee, W.H., Kang, D.H., Park, J.H., Min, S.G. and Roh, J.H. (2006) Perceived Stress, Life Style, Health Status Indicators in Medical Center Employees. Journal of Korean Academy of Community Health Nursing, 17, 407-418.

[11] Lee, W.H. and Kim, C.J. (2006) The Relationship between Depression, Perceived Stress, Fatigue and Anger in Clinical Nurses. Taehan Kanho Hakhoe Chi, 36, 925-932. https://doi.org/10.4040/jkan.2006.36.6.925

[12] Lee, N. (2011) A Case Study on Theme Presenting Type Group art Therapy to Improve Interpersonal Relationship of Angry Children. Kyungsung University, Busan.

[13] Ko, Y. (2007) Anger Expression Attitude and Interpersonal Problem: The Mediating Effect of Anger Expression Style. Master's Thesis, Chonnam National University, Gwangju.

[14] Park, S., Loh, Y., Cho, E. and Lee, D. (2011) Differences in Interpersonal Problems and Happiness by the Subgroups of Anger Expression Styles. Korean Journal of Social and Personality Psychology, 25, 77-92.

[15] Ersoy-Kart, M. (2009) Relations among Social Support, Burnout, and Experiences of Anger: An Investigation among Emergency Nurses. Nursing Forum, Wiley Online Library.

[16] Seedat, S., Scott, K.M., Angermeyer, M.C., Berglund, P., Bromet, E.J., Brugha, T.S., et al. (2009) Cross-National Associations between Gender and Mental Disorders in the World Health Organization World Mental Health Surveys. Archives of General Psychiatry, 66, 785-795. https://doi.org/10.1001/archgenpsychiatry.2009.36

[17] Park, Y. and Wee, H. (2013) The Influence of Purpose in Life, Gratitude, and Depression on Anger in Nursing College Student. Journal of the Korean Data Analysis Society, 5, 2685-2700.

[18] Chan, C.K., So, W.K. and Fong, D.Y. (2009) Hong Kong Baccalaureate Nursing Students' Stress and Their Coping Strategies in Clinical Practice. Journal of Professional Nursing, 25, 307-313. https://doi.org/10.1016/j.profnurs.2009.01.018

[19] Jun, W.-H. (2016) Trait Anger, Anger Expression, Positive Thinking and Gratitude in College Students. Journal of Korean Academy of Psychiatric and Mental Health Nursing, 25, 28-36. https://doi.org/10.12934/jkpmhn.2016.25.1.28

[20] Reeve, K.L., Shumaker, C.J., Yearwood, E.L., Crowell, N.A. and Riley, J.B. (2013) Perceived Stress and Social Support in Undergraduate Nursing Students' Educational Experiences. Nurse Education Today, 33, 419-424. https://doi.org/10.1016/j.nedt.2012.11.009

[21] Deffenbacher, J.L. (2011) Cognitive-Behavioral Conceptualization and Treatment of 
Anger. Cognitive and Behavioral Practice, 18, 212-221.

https://doi.org/10.1016/j.cbpra.2009.12.004

[22] Plutchik, R. (2003) Emotions and Life: Perspectives from Psychology, Biology, and Evolution. American Psychological Association.

[23] Spielberger, C.D. and Reheiser, E.C. (2009) Assessment of Emotions: Anxiety, Anger, Depression, and Curiosity. Applied Psychology: Health and Well-Being, 1, 271-302. https://doi.org/10.1111/j.1758-0854.2009.01017.x

[24] Krantz, D.S., Olson, M.B., Francis, J.L., Phankao, C., Merz, C.N.B., Sopko, G., et al. (2006) Anger, Hostility, and Cardiac Symptoms in Women with Suspected Coronary Artery Disease: The Women's Ischemia Syndrome Evaluation (WISE) Study. Journal of Women's Health, 15, 1214-1223.

https://doi.org/10.1089/jwh.2006.15.1214

[25] Evans, S., Giosan, C., Patt, I., Spielman, L. and Difede, J. (2006) Anger and Its Association to Distress and Social/Occupational Functioning in Symptomatic Disaster Relief Workers Responding to the September 11, 2001, World Trade Center Disaster. Journal of Traumatic Stress, 19, 147-152. https://doi.org/10.1002/jts.20107

[26] Yoo, M. (2011) The Influence of Trait Anger Expressions Caused by Job Stress of Clinical Nurses on Job Satisfaction, Organizational Commitment, and Organizational Performance. Master's Thesis, Konkuk University, Seoul.

[27] Choi, J. and Lee, Y. (2014) The Influences of Covert Narcissism, Anger Expression Styles and Empathic Ability on Interpersonal Problems of Middle School Students. The Korean Journal of Rehabilitation Psychology, 21, 77-95. 
Appendix 1: State-Trait Anger Expression Inventory (STAXI) 1 Strongly Disagree and 4 Strongly Agree.

\begin{tabular}{|c|c|c|c|c|c|}
\hline S no. & STAXI Items & 1 & 2 & 3 & 4 \\
\hline 1 & I am furious & & & & \\
\hline 2 & I feel irritated & & & & \\
\hline 3 & I feel angry & & & & \\
\hline 4 & I feel like yelling at somebody & & & & \\
\hline 5 & I feel like breaking thing & & & & \\
\hline 6 & I am mad & & & & \\
\hline 7 & I feel like banging on the table & & & & \\
\hline 8 & I feel like hitting someone & & & & \\
\hline 9 & I am burned out & & & & \\
\hline 10 & I feel like swearing & & & & \\
\hline 11 & I am quick tempered & & & & \\
\hline 12 & I have a fiery temper & & & & \\
\hline 13 & I am a hotheaded person & & & & \\
\hline 14 & I get angry when slowed down & & & & \\
\hline 15 & I get annoyed when there is no recognition & & & & \\
\hline 16 & I fly off the handle & & & & \\
\hline 17 & When I get mad, I say nasty things & & & & \\
\hline 18 & $\begin{array}{l}\text { I get furious when I am criticized in front of } \\
\text { someone }\end{array}$ & & & & \\
\hline 19 & I get frustrated and feel like hitting someone & & & & \\
\hline 20 & I am infuriated when I get poor evaluation & & & & \\
\hline 21 & I control my behavior & & & & \\
\hline 22 & I express my anger & & & & \\
\hline 23 & I keep things in? & & & & \\
\hline 24 & I am patient with others & & & & \\
\hline 25 & I become sullen & & & & \\
\hline 26 & I withdraw from people & & & & \\
\hline 27 & I make sarcastic remarks about others & & & & \\
\hline 28 & I fret? & & & & \\
\hline 29 & I do things like slamming doors & & & & \\
\hline 30 & Nothing forces me to show anger & & & & \\
\hline 31 & I control my temper & & & & \\
\hline 32 & I argue with others & & & & \\
\hline 33 & I tend to harbor grudges & & & & \\
\hline 34 & I pout or sulk & & & & \\
\hline 35 & I can stop myself from losing my temper & & & & \\
\hline 36 & I do things like slam doors & & & & \\
\hline 37 & I feel angrier than I am willing to admit & & & & \\
\hline 38 & I am irritated a great deal more & & & & \\
\hline
\end{tabular}




\section{Continued}

\begin{tabular}{cc}
\hline 39 & I say nasty things \\
40 & I have to be tolerant and comprehensive \\
41 & I argue with others \\
42 & I lose my temper \\
43 & If I am annoyed, I am apt to tell how I feel \\
44 & I control my angry feelings \\
\hline
\end{tabular}

\section{Appendix 2: Inventory of Interpersonal Problems Circumplex Scales (IIP-SC)}

\begin{tabular}{|c|c|c|c|c|c|c|}
\hline Items & $\begin{array}{l}\text { Inventory of Interpersonal Problems } \\
\text { Circumplex Scales (IIP-SC) }\end{array}$ & $\begin{array}{c}\text { Strongly } \\
\text { disagree } \\
\quad=0\end{array}$ & $\begin{array}{l}\text { Disagree } \\
\quad=1\end{array}$ & $\begin{array}{l}\text { Neutra } \\
\quad=2\end{array}$ & $\begin{array}{l}\text { Agree } \\
=3\end{array}$ & $\begin{array}{l}\text { e Strongly } \\
\text { Agree }=4\end{array}$ \\
\hline \multirow[t]{4}{*}{ Domineering } & $\begin{array}{l}\text { It is hard for me to understand } \\
\text { another person's point of view }\end{array}$ & & & & & \\
\hline & $\begin{array}{l}\text { I am too aggressive toward other } \\
\text { people }\end{array}$ & & & & & \\
\hline & I try to control other people too much & & & & & \\
\hline & I argue with other people too much & & & & & \\
\hline \multirow[t]{4}{*}{ Vindictive } & $\begin{array}{l}\text { It is hard for me to be supportive of } \\
\text { another person's goals in life }\end{array}$ & & & & & \\
\hline & $\begin{array}{l}\text { It is hard for me to feel good about } \\
\text { another person's happiness }\end{array}$ & & & & & \\
\hline & I am too suspicious of other people & & & & & \\
\hline & $\begin{array}{l}\text { I want to get revenge against people } \\
\text { too much }\end{array}$ & & & & & \\
\hline \multirow[t]{4}{*}{ Cold } & $\begin{array}{l}\text { It is hard for me to show affection to } \\
\text { people }\end{array}$ & & & & & \\
\hline & $\begin{array}{l}\text { It is hard for me to experience a } \\
\text { feeling of love for another person }\end{array}$ & & & & & \\
\hline & $\begin{array}{l}\text { It is hard for me to feel close to other } \\
\text { people }\end{array}$ & & & & & \\
\hline & $\begin{array}{l}\text { I keep other people at a distance too } \\
\text { much }\end{array}$ & & & & & \\
\hline \multirow[t]{4}{*}{$\begin{array}{l}\text { Socially } \\
\text { Avoidant }\end{array}$} & It is hard for me to join in groups & & & & & \\
\hline & $\begin{array}{l}\text { It is hard for me to introduce myself } \\
\text { to new people }\end{array}$ & & & & & \\
\hline & $\begin{array}{l}\text { It is hard for me to socialize with } \\
\text { other people }\end{array}$ & & & & & \\
\hline & $\begin{array}{l}\text { It is hard for me to ask other people to } \\
\text { get together socially with me }\end{array}$ & & & & & \\
\hline \multirow[t]{3}{*}{ Nonassertive } & $\begin{array}{l}\text { It is hard for me to tell a person to } \\
\text { stop bothering me }\end{array}$ & & & & & \\
\hline & $\begin{array}{l}\text { It is hard for me to confront people } \\
\text { with the problems that come up }\end{array}$ & & & & & \\
\hline & $\begin{array}{l}\text { It is hard for me to be assertive with } \\
\text { another person }\end{array}$ & & & & & \\
\hline
\end{tabular}




\section{Continued}

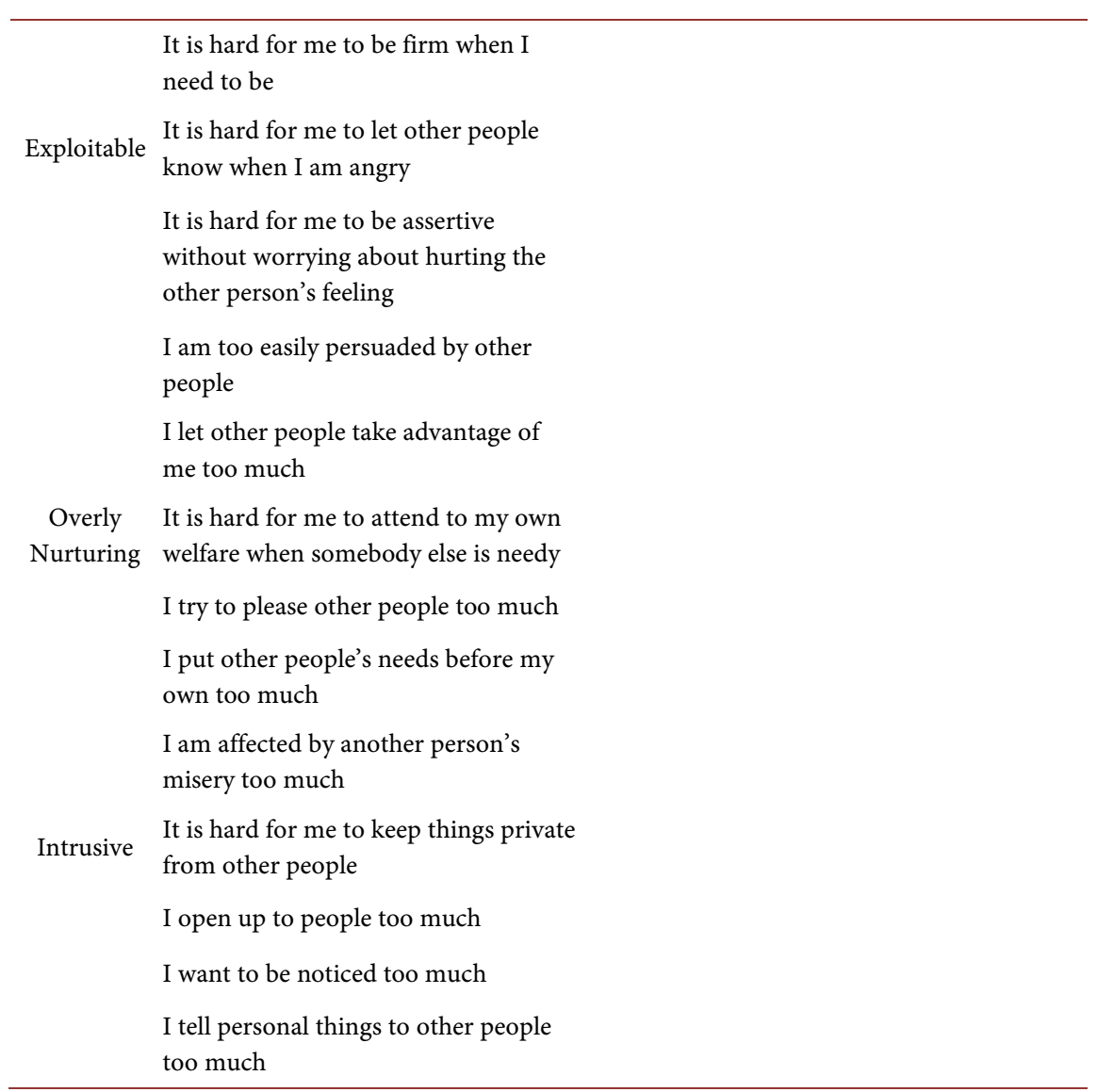

